\title{
Electrical Machines and Drives for Potentially Explosive Atmospheres
}

\author{
Colin Grantham*
}

\begin{abstract}
This paper gives an overview of the requirements for electrical equipment in potentially explosive atmospheres and describes how these are applied to electrical machines and drives in hazardous areas. The method by which equipment can be shown to be safe in a whole range of gases, by testing in a single test gas, is covered. It is shown how the more recently introduced methods of protection for hazardous areas, increased safety and nonsparking, are ideally suited to AC machines and drives. A novel method of measuring the fullload temperature rise of electrical machines for hazardous, and other areas, without the need to connect a mechanical load to the machine's drive shaft is explained.
\end{abstract}

Keywords: Hazardous zones, Gas grouping, Temperature classification, Flameproof protection, Increased Safety, Non sparking, Synthetic loading.

\section{Introduction}

The continual growth of the chemical and petrochemical engineering industries implies a corresponding increase in the number of industrial complexes involving hazards from flammable gases, vapours and mists which can produce explosive mixtures with air. There is a danger of an explosion or fire occurring wherever combustible materials are handled. Major industries include the petrochemical, chemical sewerage treatment, and grain handling industries; while smaller industries involve such areas as paint spraying workshops and drycleaning premises. In many cases the hazards occur in areas frequented by the public, for example petrol service stations. In all these situations electricity is used and is potentially capable of igniting an explosive gas mixture, either from an arc or spark or from a high surface temperature within the equipment.

To prevent any of the electrical equipment becoming a source of ignition for an explosion, special precautions have to be taken in the design, construction, installation and maintenance of such equipment.

Despite the importance of this expanding area of technology there is still a dearth of professional engineers with appreciable knowledge of the subject and concern has been expressed about the lack of proper education in this area.

This paper presents an overview of the fundamentals of electrical safety in hazardous atmospheres. It also introduces a novel method of measuring the full-load temperature rise of electrical machines without the need to connect a mechanical load to the machine's drive shaft.

\footnotetext{
School of Electrical Engineering and Telecommunications, The

University of New South Wales, Sydney, Australia.

(c.grantham@unsw.edu.au)
}

Received 06 July 2011; Accepted 19 October 2011

\section{Hazardous Zones}

The likelihood of an ignition of gas occurring is dependent on the probability of an explosive mixture of gas being present at the same time as the electrical apparatus produces an ignitable source (i.e. an arc or spark or a hot surface). Hazardous areas are therefore classified into zones, according to the likelihood of a flammable gas mixture being present. These zones are defined as follows:
Zone 0 - area in which explosive mixture exists more or less continuously, (for IEC/Europe > $1000 \mathrm{hrs} /$ year);

Zone 1 - area in which gas is not normally present but is likely to occur from time to time, ( $>10 \mathrm{hrs} /$ year);

Zone 2 - area in which an explosive mixture is likely only in abnormal conditions and for short periods ( $>0.1 \mathrm{hrs} /$ year).

Areas can be zoned by specific occupancy, i.e. commonly occurring situations such as finishing processes, petrol dispensing pumps etc. These specific occupancies are listed in national and international standards such as AS/NZS 2430.3.2:2004[1]. Where there is no specific occupancy, assessment of hazardous zones can be carried out by using the methods given in AS/NZS 60079.10.1:2009 [2].

As in most forms of engineering there has to be an acceptable balance between cost and performance. It is clear that equipment for use in a Zone 0 area, should afford a greater degree of protection than equipment for use in a Zone 2 area. This does not mean that the equipment in 
the Zone 2 area is any less safe, since it is the combination of an explosive mixture and an ignition source which is to be avoided. The ideal engineering solution would be if the statistical probability of an explosive mixture and an ignition source being present, at the same time, was the same in each case and of course was acceptable.

\section{Gas Grouping}

There are so many gaseous mixtures that to ensure equipment is safe, by test, in all gases would take an exorbitant amount of time and the cost would, in most cases, be prohibitive. It can be shown by test that gases may be grouped, such that if the equipment passes the prescribed tests relative to one gas (known as the test gas for that group), the equipment will be safe for use in all gases in that group (and if applicable in any other less severe group). The four groups into which gases have been categorized are:

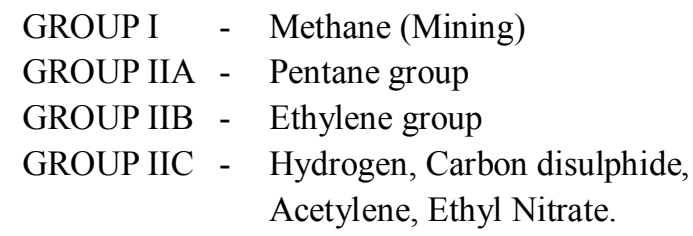

Of these, group IIC gases are the most easily ignited, followed by IIB, IIA and group I. Similarly group IIC gases have flame propagation properties necessitating the most stringent design requirements for flameproof enclosures which will be considered later. If apparatus has been shown to be safe in the group IIC test gas, then it is safe for all group IIC gases and because gas groups IIB and IIA are less stringent, the equipment would in fact be suitable for all gas groups. Equipment which was shown to be suitable for group IIB gases, would also be suitable for group IIA gases, but would not be suitable for group IIC gases. [Mining applications usually involve special considerations because of the extremely harsh physical environment].

By using this method of gas grouping the process of ensuring equipment is safe in a wide range of gases can be streamlined.

\section{Temperature Classification}

To further streamline safety assessment, equipment is given one of six temperature classifications, based on a reference ambient of $40^{\circ} \mathrm{C}$, as shown in Table 1 .
The temperature classification is based on the maximum internal or external temperature (depending upon the type of protection used) and this classification is stamped on the equipment nameplate; the equipment can be used in any gases with ignition temperatures above the temperature classification, subject to the group limitations referred to above.

Some examples of chemical compounds, their ignition temperature and gas groupings are shown in Table 2 . It is interesting to note that there appears to be no correlation between a gas's affinity to be ignited with a spark and its auto-ignition temperature, e.g. hydrogen is one of the gases most readily ignited by a spark, yet its auto-ignition temperature is one of the highest. (Smokers can feel reassured that the ignition temperature of nicotine is well above body temperature!).

Table 1. Temperature classification

\begin{tabular}{|c|c|}
\hline Temperature class & $\begin{array}{c}\text { Maximum surface temperature } \\
\text { Surfaces freely accessible to } \\
\text { surrounding atmosphere }\left({ }^{\circ} \mathrm{C}\right)\end{array}$ \\
\hline $\mathrm{T} 1$ & 450 \\
\hline $\mathrm{T} 2$ & 300 \\
\hline $\mathrm{T} 3$ & 200 \\
\hline $\mathrm{T} 4$ & 135 \\
\hline $\mathrm{T} 5$ & 100 \\
\hline $\mathrm{T} 6$ & 85 \\
\hline
\end{tabular}

Table 2. Ignition temperature and gas groupings for some common compounds

\begin{tabular}{|c|c|c|c|}
\hline Compound & $\begin{array}{c}\text { Chemical } \\
\text { formula }\end{array}$ & $\begin{array}{c}\text { Ignition } \\
\text { Temp. }{ }^{\circ} \mathrm{C}\end{array}$ & Gas group \\
\hline Acetaldehyde & $\mathrm{CH}_{3} \mathrm{CHO}$ & 140 & IIA \\
\hline Ammonia & $\mathrm{NH}_{3}$ & 630 & IIA \\
\hline Benzene & $\mathrm{C}_{6} \mathrm{H}_{6}$ & 555 & IIA \\
\hline $\begin{array}{c}\text { Carbon } \\
\text { disulphide }\end{array}$ & $\mathrm{CS}_{2}$ & 102 & IIC \\
\hline Ethylene & $\mathrm{CH}_{2}=\mathrm{CH}_{2}$ & 425 & IIB \\
\hline Hydrogen & $\mathrm{H}_{2}$ & 560 & IIC \\
\hline $\begin{array}{c}\text { Hydrogen } \\
\text { sulphide }\end{array}$ & $\mathrm{H}_{2} \mathrm{~S}$ & 270 & IIB \\
\hline Methane & $\mathrm{CH}_{4}$ & 595 & I \\
\hline Nicotine & $\mathrm{C}_{10} \mathrm{H}_{14} \mathrm{~N}_{2}$ & 240 & IIA \\
\hline
\end{tabular}

Having categorized hazardous locations into zones representing the degree of hazard, grouped gases together based on their affinity to be ignited and propagate a flame 
and finally introduced a temperature classification identifying the maximum surface temperature, the various methods of protection, applicable to electrical equipment for use in hazardous locations can be considered.

\section{Flameproof Protection}

A flameproof enclosure is essentially one which can withstand an internal explosion and prevent the ignition of external gases. It is basically a mechanical form of protection, which works on the basis that as a flame (explosion) attempts to spread from the inside to the outside of an enclosure it is cooled to such an extent that any gas surrounding the enclosure will not be ignited. All flameproof enclosures must comply with certain dimensional requirements depending on the particular gas group to be covered.

Flame-paths (length in air between inside and outside of enclosure) must be a minimum length and flame gaps (air space between mating surfaces) must not be above a prescribed maximum dimension. As the flame-path is increased and the flame gap decreased, the extinguishing effect of any flame trying to "escape" from the enclosure is increased. Threaded joints must have a minimum number of threads engaged. Cables must enter the enclosure via flameproof glands, or if conduit is used a "stopper" (encapsulated) fitting is required. Windows must be tough and must be sealed to prevent transmission of an explosion. Spindles and rotating shafts must comply with special dimensional requirements; rotating shafts must pass through special flameproof glands. The equipment must be tamperproof to prevent unauthorized entry.

Every production enclosure must be subjected to a routine pressure test of 1.5 or 3 times the maximum pressure attained during test with the prescribed gas, according to whether the peak pressure rise time is greater, or less than, $5 \mathrm{~m}$. sec, respectively. Fig. 1 shows how the pressure rise time is evaluated. Provided that the dimensional and strength requirements of the certification standard are complied with, the enclosure will almost certainly pass its prescribed test.

Electric motors have their flameproof enclosures incorporated into the design and end up looking similar to a conventional industrial motor. Fig. 2 shows an example of a $485 \mathrm{~kW}, 2979 \mathrm{rev} / \mathrm{min}, 3.3 \mathrm{kV}$, flameproof motor. The power electronics part of a drive system needs to be enclosed within a flameproof housing of the type described above for this type of protection.

It is normal practice when testing a flameproof enclosure to fill the enclosure and surrounding volume with some prescribed gas mixture and ignite the mixture in the enclosure with a sparking plug. The test is repeated several times, enclosure pressure and rise time are measured and it is ensured that an explosion is not transmitted to the external gas mixture.

Flameproof equipment is generally accepted for use in Zone 1 areas. It can be applied to most types of electrical

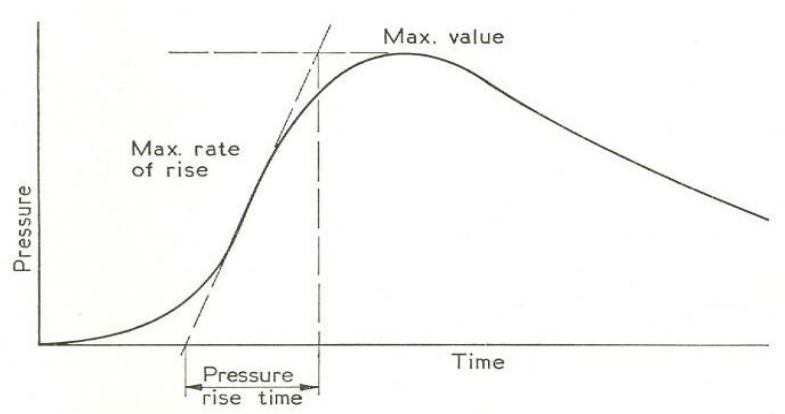

Fig. 1. Pressure rise in flameproof enclosure.

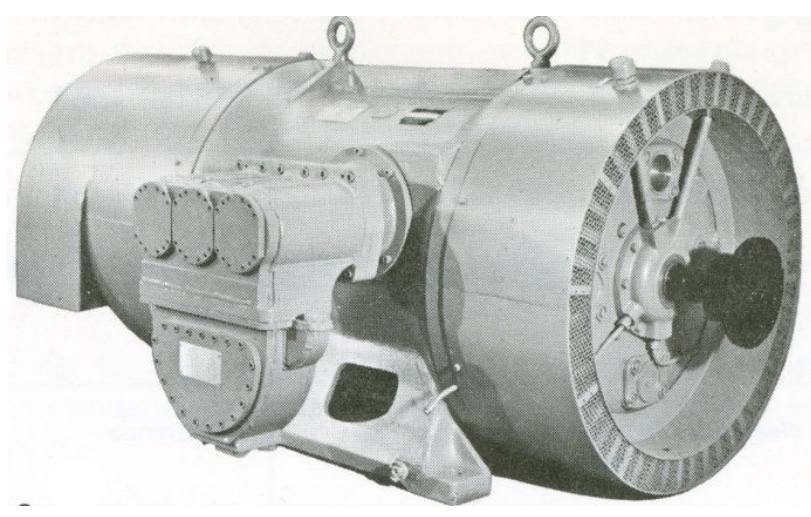

Fig. 2. Example of flameproof induction motor.

equipment and is very well suited to switchgear which cannot be protected by most of the other methods of protection. Flameproof equipment is inherently robust and this makes it particularly attractive for very harsh environments such as mining, where equipment has to be designed to withstand mechanical damage. It is a well proven method of protection, which over the years has been shown to be very safe.

In larger sizes, flameproof enclosures are heavy and expensive and are often difficult to make weatherproof and maintain.

\section{Increased Safety and Non Sparking Protection}

For certain types of equipment, protection can be achieved without the same weight or cost penalty incurred with the use of flameproof equipment. Any equipment 
which does not produce an arc or a spark in normal use, nor produce a surface temperature sufficiently high to ignite gas, can be considered applicable to two relatively new concepts known a increased safety (type 'e') or nonsparking (type ' $n$ '). Squirrel-cage induction motor drives fit very neatly into the types of equipment which can be considered by these methods of protection.

Although these two methods of protection are covered by their own certification standards $[3,4]$ it is convenient to consider them together since they are similar in concept, differing only in degree. Type 'e' equipment can in general be used in a Zone 1 area and type ' $n$ ' equipment in a Zone 2 area.

Both these methods of protection rely on additional measures applied to equipment of normal construction, to give increased security against excessive temperatures and of the occurrence of arcs, or sparks, during the service life of the equipment. To illustrate the protection concept, it is instructive to consider a simple piece of electrical equipment, a terminal box. Fig. 3 shows a type 'e' terminal box.

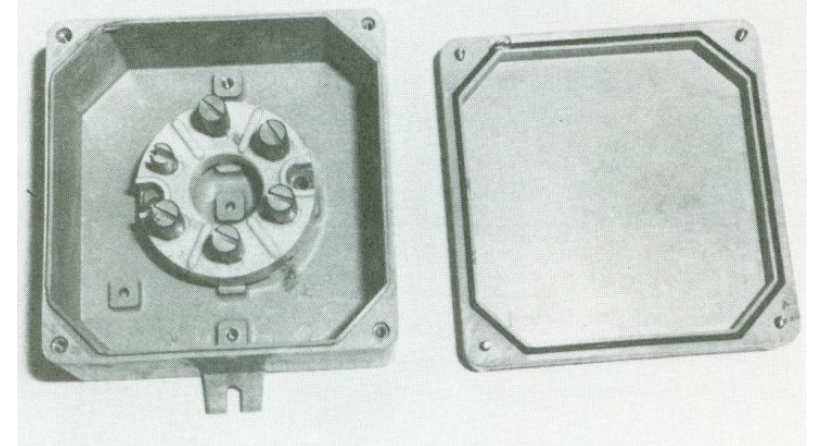

Fig. 3. Increased safety terminal box.

The terminal box must be weatherproof and the enclosure must have mechanical strength and be thermally and chemically stable; these requirements are to prevent the enclosure terminals being contaminated, which could in turn lead to electrical surface tracking. Cable entry must also be via a robust weatherproof cable gland. The terminals themselves must have some anti-vibration feature to prevent them coming loose and the clearance and creepage distances must comply with a specified minimum value, depending upon the voltage between adjacent terminals. The terminal block material must comply with a minimum specified comparative tracking index, depending upon the creepage distance between terminals and the voltage used.

A type ' $n$ ' motor is not too different from its standard industrial counterpart. An example of a type ' $n$ ' cage motor rated at $1865 \mathrm{~kW}, 6.6 \mathrm{kV}, 1485 \mathrm{rev} / \mathrm{min}$ is shown in Fig. 4.

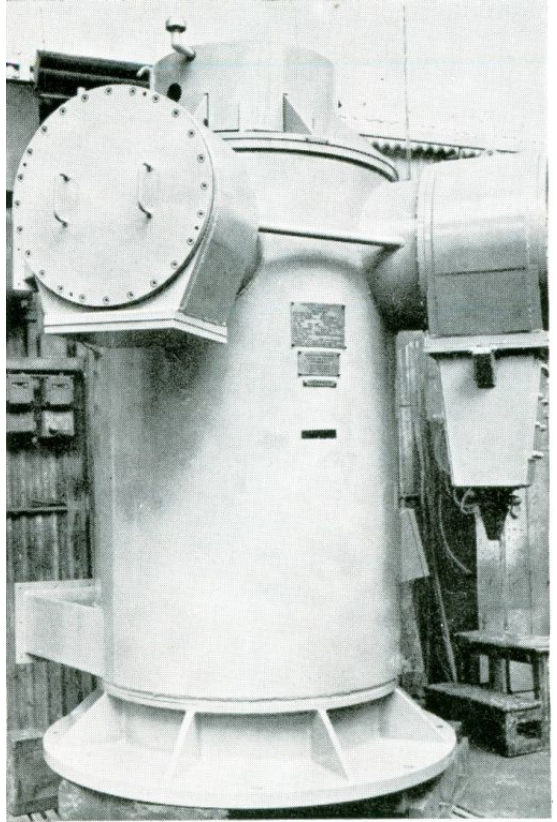

Fig. 4. Example of type 'n' motor.

A type ' $n$ ' motor must have a terminal enclosure which complies with the requirements outlined above. The temperature classification of type ' $n$ ' machines is based upon the operating conditions excluding starting conditions unless a machine is designed to operate under duty cycle conditions, in which case the limiting temperature determined by the temperature class of the motor must not be exceeded for the whole of the duty period, including starting if this is part of the duty cycle. Fans, fan- hoods, ventilation screens, and the like, must be strongly constructed and fixed so as to prevent any distortion and displacement which could cause impact or friction of rotating parts against fixed parts. In normal operation, the clearance between the fan, hood and screen and their fasteners must be at least $1 \%$ of the maximum diameter of the fan and not less than $1 \mathrm{~mm}$. This clearance need not, however, exceed $5 \mathrm{~mm}$ and may be reduced to $1 \mathrm{~mm}$ if the opposing parts are machined.

With type ' $n$ ' equipment the power electronics need not be housed in a flameproof enclosure but may be located in a normal weatherproof enclosure. The electronics must comply with the creepage and clearance requirements of the standard [4] and any terminal connections would have to be of the non-sparking type.

Whilst the temperature classification for type ' $n$ ' motors is based on full load conditions, for type 'e' motors it is based on a stalled rotor test. Increased-safety motors are also given a te time, this being the time taken for the motor to reach a critical temperature when stalled. The te time is either the time taken for the rotor to reach a temperature capable of igniting gas, or the time taken for the stator winding 
to reach a temperature which could prematurely damage the winding insulation and thereby produce a short circuit between windings capable of igniting gas. The lower of the two times is taken, and is measured after, or referred to, worst previously operating conditions (i.e. full load conditions in a maximum ambient temperature of $40^{\circ} \mathrm{C}$ ). Fig. 5 shows the te time in relation to certain maximum operation temperatures.

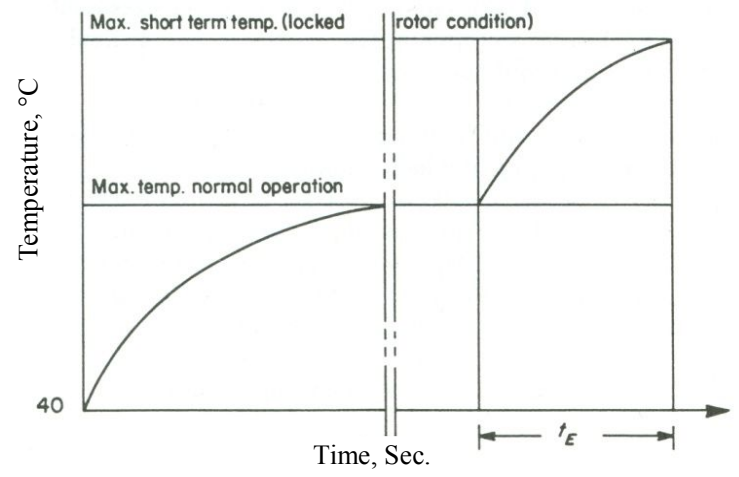

Fig. 5. $\mathrm{T}_{\mathrm{E}}$ time for a type 'e' motor.

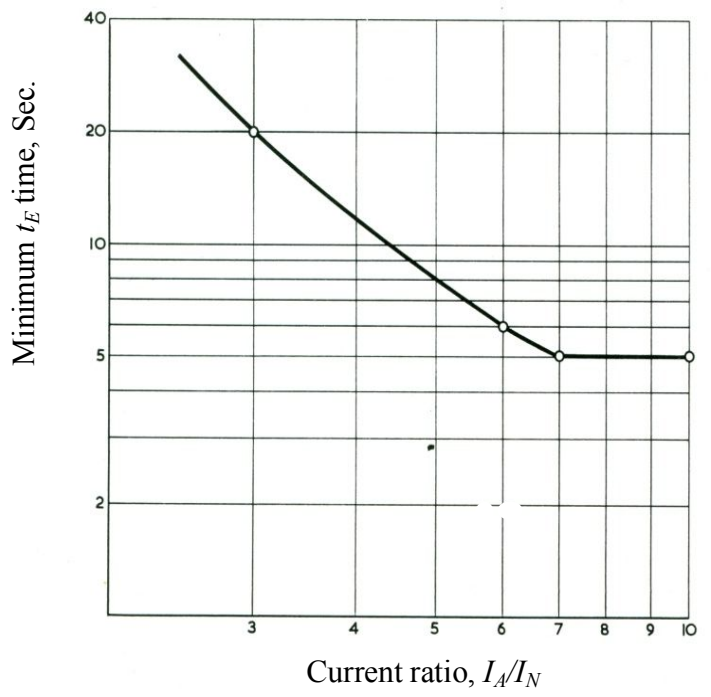

Fig. 6. Minimum value of $t_{E}$ time for a type 'e' motor.

For machines with cage rotors, including synchronous machines with cage rotors for starting, the starting current to normal running current ratio $\left(\mathrm{I}_{\mathrm{A}} / \mathrm{I}_{\mathrm{N}}\right)$ is also determined in order to provide for the selection of a suitable current detection device to protect against the occurrence of nonpermissible temperatures.

The length of time tE must be such as will allow, when the rotor is locked, the motor to be disconnected by the current dependent protective device before time $t_{\mathrm{E}}$ has elapsed. In general this is possible if the minimum values for te shown in Fig. 6 as a function of the starting current ratio $\mathrm{I}_{\mathrm{A}} / \mathrm{I}_{\mathrm{N}}$ are exceeded.

Values of te below the values in Fig. 6 are permissible only if a suitable overload protection device is used for the machine and it is shown to be effective by test. In no case is the value of te time permitted to be less than $5 \mathrm{~s}$ nor the current ratio $\mathrm{I}_{\mathrm{A}} / \mathrm{I}_{\mathrm{N}}$ allowed to exceed 10 . For machines rated at more than $160 \mathrm{~kW}$, the starting current ratio, $\mathrm{I}_{\mathrm{A}} / \mathrm{I}_{\mathrm{N}}$, the temperature rise in rated service and the te time may alternatively be calculated.

Fig. 7 shows a type 'e' motor ready for its full voltage locked rotor tests and Fig. 8 shows typical results for a machine which has undergone such tests.

As with type ' $n$ ' motors there are requirements relating to fan clearances and in addition there is a minimum radial air gap requirement which is dependent upon the rotor diameter, maximum speed of rotation and core length. There are also special requirements relating to thermal stability, winding insulation and minimum size of conductors which may be used in the machine.

With type 'e' variable speed drives there is no equivalent type ' $n$ ' protection for the power electronic converter and in general these latter components need to be installed in a flameproof enclosure or covered by some other method of hazardous atmosphere protection, e.g. pressurization or purging [5].

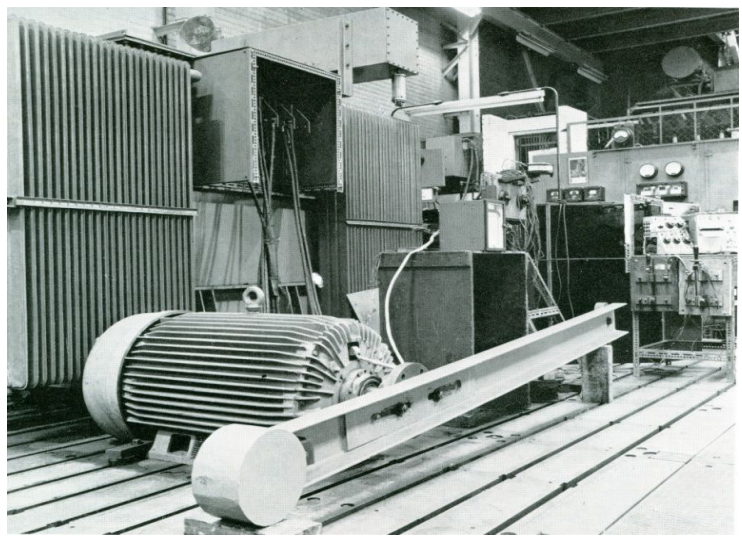

Fig. 7. Type 'e' motor with rotor locked.

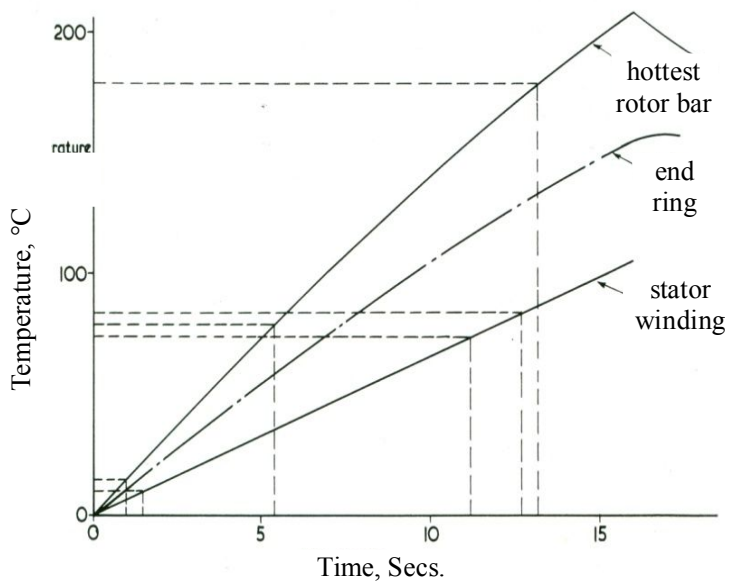

Fig. 8. Temperature rise cnaracteristics for a type 'e' motor during locked rotor test. 
With type 'e' and ' $\mathrm{n}$ ' equipment, a method of protection exists which requires little more than the application of good engineering practice. Obviously this method of protection is very attractive from an economic point of view and allows non-specialist manufacturers to have their equipment approved for use in hazardous locations; hitherto only specialist manufacturers had tended to produce flameproof equipment.

These new methods being essentially quality concepts have the additional advantage that the equipment tends to be more reliable and have a longer life; this type of equipment is sometimes even used in non hazardous areas simply because of the economic advantages which stem from this greater reliability.

To give type ' $e$ ' equipment the necessary added security, it is often necessary to de-rate it relative to its normal industrial use; this de-rating can sometimes make it less economically attractive than its flameproof counterpart, particularly for small equipment.

\section{Synthetic Loading}

The following briefly describes methods of synthetic loading to evaluate the full load temperature rise of hazardous atmosphere, and other, three-phase induction motors without the need to connect a mechanical load to the machine's drive shaft. The novel method uses microprocessor, or DSP, controlled power electronic techniques to cause the motor to continuously accelerate and slow down over a narrow speed range close to the normal operating speed.

Two methods of synthetic loading are described, one method uses microprocessor, or DSP, controlled power electronics to generate two distinct frequencies and thereby replace the electrical machines of the existing dual frequency equivalent load technique [6]. The second method uses microprocessor, or DSP, controlled power electronics to rapidly change the machine's supply frequency.

The tests are carried out for an industrial type $7.5 \mathrm{~kW}$ squirrel-cage induction machine using the different synthetic loading techniques, and also using a conventional dynamometer for comparison of results.

The essence of the dual frequency method referred to above is to produce a supply containing two distinct frequencies; this has the effect of producing two fields rotating at different speeds, $\omega_{\mathrm{a}}$ and $\omega_{\mathrm{b}}$.

If all quantities are represented as per unit values, for sinusoidal voltages the flux can be set equal to the supply voltages, divided by frequency. With two voltages, $\mathrm{V}_{\mathrm{a}}$ and $\mathrm{V}_{\mathrm{b}}$, in series, the total flux, $\Phi_{\mathrm{t}}$, is the sum of two flux waves of different magnitude and frequency.

Fig. 9 shows these vectors rotating at different angular velocities. Schwenk [6] analysed these two rotating vectors and showed that the magnitude and angular velocity of the resultant flux varies as a function of time, supply voltages and frequencies.

Because of the inertia of the rotor, the varying angular velocity of the resultant flux wave causes alternating induction motor-generating action, thus increasing the effective RMS current flowing in the machine.

An alternative method of establishing the effect of the two individual supplies is to consider the motor running at a speed between that of the two supplies. The machine therefore draws motoring current with respect to the higher speed field and supplies generating current with respect to the lower speed field. The two currents beat together to form a modulated current whose RMS value over a period, greater than the beat period, can be made equivalent to the normal load current for the machine by adjusting the amplitudes and frequencies of each component.

This method which previously required a system of electrical machines to generate the two frequencies, can be very conveniently implemented using microprocessor or DSP controlled power electronics to generate the necessary voltages and frequencies for the two supplies.

Another method of artificially increasing the motor current is to use a single supply frequency, but to rapidly modulate this frequency over a small range centered on the rated frequency. This also causes alternating induction motor-generator action. This method of synthetic loading cannot be implemented by using an electrical machine power source, as with the former method, because it is not possible to produce the required rapid modulation of frequency. However, by using microprocessor, or DSP, controlled power electronics, the necessary modulation can be achieved and this is the basis upon which the second method is implemented.

A microprocessor, or DSP, may be used to generate the necessary logical control for a PWM inverter. The DSP calculates the pulse widths to control the output in real time by sine table lookups and multiplication. This system is not constrained by hard wired logic. The software may be changed to produce output waveforms other than simple sine functions.

The new synthetic loading full load temperature rise evaluation technique gives results which are in excellent agreement with the conventional dynamometer method. 


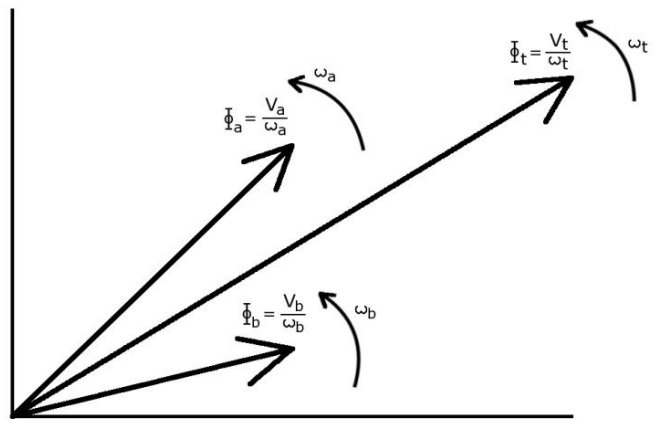

Fig. 9. Phasor diagram of rotating flux waves.

The new method will enable motors to be tested at virtually any location including on site. The equipment will require no external load to be connected to the test machine's drive shaft; setting up time will therefore be considerably reduced, particularly for large machines. A complete description of the new synthetic loading method together with test results is included at reference [7].

\section{Conclusions}

There are so many gaseous mixtures that to ensure equipment is safe, by test, in all gases would take an exorbitant amount of time and the cost would, in most cases, be prohibitive. However, it can be shown by test that gases may be grouped, such that if the equipment passes the prescribed tests relative to one gas, known as the test gas for that group, the equipment will be safe for use in all gases in that group and if applicable in any other less severe group.

The process of safety assessment can be further streamlined by giving equipment one of six temperature classifications based on a reference ambient of $40^{\circ} \mathrm{C}$.

Categorizing hazardous areas into one of three hazardous zones ensures that the cost of achieving safety is not excessive for the degree of risk involved.

There is now a choice of methods of protection applicable to electrical machines and drives for use in potentially explosive atmospheres. The older flameproof method is well established and has, over the years, proved to be very safe in practice. In larger sizes, flameproof drives are often heavy, expensive, and difficult to make weatherproof and maintain.

Increased safety and type ' $\mathrm{n}$ ' protection can be applied to electrical machines and drives which do not produce an arc or spark in normal operation. These latter methods, particularly increased safety, have the advantage of generally being more reliable and having a longer life and are sometimes used in non hazardous areas simply because of their greater reliability.

\section{References}

[1] AS/NZS 2430.3.2:2004, "Classification of hazardous areasExamples of classification-Vehicle workshops, vehicle parking, fuel dispensing stations and aircraft hangers".

[2] AS/NZS 60079.10.1:2009 "Explosive atmospheresClassification of areas-Explosive gas atmospheres (IEC60079-10-1)".

[3] AS/NZS 60079.7:2006, "Explosive atmospheres-Equipment protection by increased safety ' $\mathrm{e}$ '",

[4] AS/NZS 60079.15:2006, "Electrical apparatus for explosive gas atmospheres-Construction, test and marking of type of protection 'n' electrical apparatus".

[5] AS2380.4:1994, "Electrical equipment for explosive atmospheres-Explosion protection techniques-Pressurized rooms or pressurized enclosures".

[6] H.R. Schwenk, "Equivalent loading of induction machines for temperatures tests", Trans. IEEE, Vol. PAS-96, No 4, pp 1126-1131, July/August 1977.

[7] Grantham, C., and McKinnon, D., "A rapid method for load testing and efficiency measurement of three-phase induction motors", Proc. ICEMS2008, Wuhan, China, 17-20 Oct. 2008, Paper No. DMO-09, pp1-6.

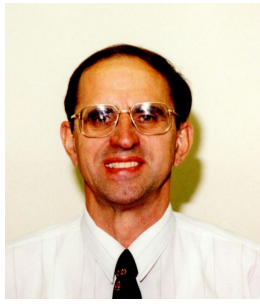

Colin Grantham received his BSc and $\mathrm{PhD}$ from the University of Newcastle-upon-Tyne (UK) in 1969 and 1972 respectively. He then joined the British Approvals Service for Electrical Equipment in Flammable Atmospheres (BASEEFA) where he helped to introduce new types of hazardous atmosphere protection in the United Kingdom. In 1975 he moved to the Military Vehicles and Engineering Establishment (MVEE) where he stayed until 1981 when he took up a post as lecturer in the School of Electrical Engineering and Computer Science at the University of New South Wales, Australia. He is at present a visiting Professorial Fellow in the School of Electrical Engineering and Telecommunications at that University. His research interests cover the fields of electrical machines and drive systems, electrical safety and electrical equipment for hazardous atmospheres. 